Aus dem Georg-Speyerhaus in Frankfurt a. M.

(Direktor: Exz. Wirkl. Geh.-Rat Prof. Dr. Paul Ehrlich.)

\title{
Zur Topographie des Salvarsans und Neosalvarsans.
}

\author{
Von Dr. A. Stühmer, \\ z. Z. Assistent an der königl. Universitätsklinik zu Breslau.
}

Über das Schicksal der Salvarsanverbindungen im Körper sind in letzter Zeit maninigfache Arbeiten veröffentlicht worden. Es liegt ja auf der Hand, daß bei einem Mittel, welches einesteils so große Hoffnungen, anderenteils aber auch bei vielen so große Befürchtungen geweckt hat, wie das Salvarsan, die Frage besonders interessiert, wo das in den Körper eingeführte Medikament bleibt, wie es sich im Blute, in den Organen verhält, in welcher Weise es sich verteilt und wie lange es im Körper verweilt. In der Hauptsache nun erstreckten sich die Versuch?, welche zur Klärung aller dieser Fragen bisher unternommen wurden, auf das Studium der Ausscheidungsverhältnisse. Die Bestimmung des in den Ausscheidungen vorhandenen Arsens diente hier meist als Anhaltspunkt.

Es würde zu weit führen, hier auf alle diese Ergebnisse näher einzugehen. Es sei nur kurz zusammenfassend gesagt, daß man anfänglich annahm, das Arsen verlasse den Körper nach der intravenösen Einspritzung sehr schnell wieder. Allmählich aber brach sich die Erkenntnis Bahn, daß die Ausscheidung doch wesentlich langsamer von statten geht, so daß auch nach intravenöser Einverleibung unter Umständen noch nach 1-3 Monaten Spuren Arsen nachweisbar sind. Es erschien deshalb wichtig, sich einen genaueren Einblick in die topographischen Verhältnisse der Salvarsanverteilung im Körper zu verschaffen.

Auf Veranlassung von Exzellenz Ehrlich habe ich eingehende Untersuchungen über diesen Standpunkt angestellt. Und zwar benutzte ich die von Ehrlich und Berthei an angegebene Reaktion der Salvarsanverbindungen mit dem Paradimethylamidobenzaldehyd. 
Ich stellte das Reagens so her, daß ich eine kleine Menge Paradimethylamidobenzaldehyd in einigen Tropfen reiner Salzsäure löste, dazu gesättigte wässerige Sublimatlösung in reichlichem Überschuß gab und den bei kräftigem Schütteln alsbald auftretenden flockigen Niederschlag mit einigen Tropfen reiner Salzsäure wiederum zur Lösung brachte. Mit dieser Lösung geben die Salvarsanverbindungen einen gelben bis orangefarbigen Niederschlag, der in der überschüssigen gesättigten Sublimatlösung unlöslich ist. Es ist notwendig, die Lösung stets frisch herzustellen, da ältere Lösungen nur schwache oder gar keine Reaktion mehr ergeben. Die stärksten Reaktionen erhielt ich, wenn ich die Sublimatlösung leicht erwärmte, bevor ich sie der salzsauren Lösung des Paradimethylamidobenzaldehyds zusetzte und dann das noch warme Reagens verwendete (s. u. bei Untersuchung des Blutserums).

Das Reagens erwies sich als ausgezeichnet brauchbar. Über ähnliche Versuche, das Salvarsan in den Organen und Körpersäften nachzuweisen, berichtet Ullmann (Wien. klin. Wochenschr. 1913, Nr. 23, p. 929). Er erhielt jedoch mit der von Justus (Dermatol. Zeitschr. 1905, Bd. XII, Heft 5) angegebenen Methode, bei der das Arsen als As-Trisulfit nachgewiesen wird, keine Resultate. Ferner verwendete er auch das Ehrlich-Bertheimsche Reagens. Er fand es aber ebenfalls nicht in dem gewünschten Maße brauchbar. Im Blutserum konnte er das Salvarsan 1 Stunde nach der Injektion nachweisen, ebenso auf der Schleimhaut des Nierenbeckens. Zum Nachweis in den Organen erschien es ihm ungeeignet.

Wir verfuhren bei unseren Untersuchungen folgendermaßen: Zur Untersuchung gelangte Salvarsan in saurer und alkalischer Lösung und Neosalvarsan. Die Tiere (Kaninchen) erhielten in verschiedener Konzentration von diesen Präparaten Mengen eingespritzt, welche wenig unter der Maximaldosis lagen. Bei Altsalvarsan wurde in der Regel $0.075 \mathrm{pr}$. $\mathrm{kg}$, bei Neosalvarsan 0,2 gegeben. Bei saurem Altsalvarsan konnte wegen der höheren Toxizität die Dosis von $0.03 \mathrm{pr}$. $\mathrm{kg}$ nicht überschritten werden. $W_{0}$ es uns aut vergleichende Untersuchungen zwischen Altsalvarsan und Neosalvarsan ankam, wurden die Neo-Dosen auf das darin enthaltene Altsalvarsan 
umgerechnet und so den Tieren genau gleiche Mengen Salvarsan in beiden Formen einverleibt. Als Applikationsart wählten wir lediglich die intravenöse, da bei subkutaner und intramuskulärer Injektion $\mathrm{zu}$ viele örtlich bedingte unberechenbare Faktoren mitspielen (Resorption, lokale Reaktion, Nekrosen). Die Tiere wurden verschieden lange Zeit nach der Injektion getötet durch Entbluten, um die Reaktion in den Organen nicht durch den Blutgehalt zu stören bzw. um nicht durch positive Reaktion des Blutes in der Beurteilung der Organe irregeführt zu werden. Das Blutserum wurde in jedem Falle gleich frisch untersucht, die Organe mit dem Kohlensäuremikrotom geschnitten und die Schnitte sofort in die Lösung übertrager. Die Verfärbung der Organschnitte war in den meisten Fällen schon makroskopisch mit hinreichender Deutlichkeit zu erkennen, zuweilen wurde die Lupe oder das Mikroskop bei schwächster Vergrößerung zu Hilfe genommen. Feinere Einzelheiten allerdings, etwa Verteilung der Niederschläge in einzelnen Gewebsabschnitten, Zellgruppen etc. konnten in der Regel nicht erkannt werden, da die Gewebe in der stark sauren und konzentrierten Sublimatlösung zu stark durch Koagulation verändert wurden. Hier liegen demnach die Grenzen der Verwendbarkeit des Reagens. Es lassen sich wohl die Verhältnisse grobmakroskopisch zur Darstellung bringen, auch wohl zuweilen gröbere Gewebsabschnitte differenzieren, aber zum mikroskopischen Nachweis ist das Reagens leider nicht geeignet. Schleimhäute werden durch einfaches Aufträufeln der Flüssigkeit untersucht, ebenso die Dura der Schädelbasis und des Rückenmarkkanals. Die Beurteilung des Grades der Verfärbung erfordert einige Übung, kann aber dann mit hinreichender Sicherheit ausgeführt werden. Die verschiedenen Grade wurden in den Protokollen durch eine entsprechende Zahl von Zeichen eingetragen.

\section{A. Blutserum.}

Um hier die Frage zu entscheiden, wie lange mit der Reaktion noch Salvarsan im Serum nachgewiesen werden kann, wurde zunächst so verfahren, daß dem gleichen Tiere in verschiedenen Zeiträumen nach der Injektion je etwa $12 \mathrm{ccm}$ Blut 
entnommen wurde, dessen Serum dann untersucht wurde. Es stellte sich jedoch heraus, daß dieses Verfahren eine Fehlerquelle hatte in den immerhin recht beträchtlichen wiederholten Blutentnahmen. Durch jenen regelmäßig bis zu fünfmal wiederholten Aderlaß wurde die Ausscheidung des Präparates entschieden beschleunigt. Und zwar wird da nicht so sehr die Entfernung des jedesmal in dem entnommenen Blute enthaltenen Salvarsans eine Rolle spielen, als vielmehr die Anregung des gesamten Stoffwechsels, der Blutbildung etc. überhaupt. Wir änderten deshalb die Versuchsanordnung so, daß wir soviel Kaninchen spritzten, wie Blutentnahmen beabsichtigt waren. Die Zeit der Injektion wurde so für jedes Tier für die gemeinsame Blutentnahme berechnet, was weiter bei den unten beschriebenen Heil- und In vitro-Versuchen mit dem Salvarsanserum den Vorteil hatte, daß hier genau gleich alte Sera zur Verwendung kommen konnten.

Die einzelnen Blntproben wurden detibriniert, das Serum abzentrifugiert und in Mengen von $1 / 2 \mathrm{ccm}$ mit etwa $3 \mathrm{ccm}$ Reagens zusammengebracht und kräftig geschüttelt. Es tritt dabei eine Fällung auf, die aber die Beurteilung der Farbreaktion in keiner Weise stört. Natürlich müssen die Sera frei von Blutkörperchen und möglichst auch von gelöstem Blutfarbstoff sein, da sonst die auftretende schokoladenbraune Farbe irreführen kann. Normales Serum gab uns niemals eine Gelbfärbung. Im Laufe der Untersuchungen stellte es sich nun heraus, daß die Reaktion im Blutserum, wie oben bereits kurz erwähnt, durch Verwendung von frischem, noch warmem Reagens erheblich empfindlicher wird. In der Tafel I (siehe nebenstehende Tabelle) habe ich die Resultate meiner Untersuchungen zusammengestellt.

Was zunächst die saure Salvarsanlösung angeht, so war die Reaktion nur unmittelbar nach der Injektion von erheblicher Stärke. Sie nahm dann in den ersten Stunden schneller ab, als bei den anderen Präparaten. Ich glaube nicht, daß dieses Verhalten ausschließlich eine Folge der wesentlich kleineren Dosis ist, sondern daß hier doch die Ausfällung des Mittels in der alkalischen Blutflüssigkeit eine erhebliche Rolle spielt. Die schwache Reaktion hielt sich im Verlauf der ersten 
Zur Topographie des Salvarsans und Neosalvarsans.

\begin{tabular}{|c|c|c|c|c|c|c|c|}
\hline & ن & $\dot{1}$ & $\dot{x}$ & $\dot{3}$ & ند & $\dot{k}$ & $\dot{B}$ \\
\hline$\theta 8 \mathrm{R}_{\mathbf{L}} \mathrm{OK}$ & & & 1 & 1 & & & 11 \\
\hline 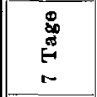 & & & I & $\begin{array}{l}\dot{0} \\
+ \\
+\end{array}$ & & & 11 \\
\hline 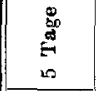 & & & 11 & $\begin{array}{l}\dot{2} \\
+ \\
+\end{array}$ & & & 11 \\
\hline 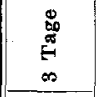 & & 1 & . & $\begin{array}{r}+\dot{2} \\
+ \\
\end{array}$ & & 11 & 11 \\
\hline 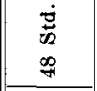 & 11 & 111 & 111111 & $\begin{array}{r}1+++\dot{0} \\
++ \\
\end{array}$ & 111 & 111 & 11 \\
\hline 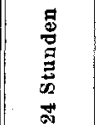 & $\begin{array}{l}\dot{2} \\
+1\end{array}$ & $\begin{array}{l}\dot{2} \dot{0} \\
0 \sin \\
+++\end{array}$ & $\begin{array}{l}\dot{8} \\
+1\end{array}$ & & 111 & $\begin{array}{ll}\dot{2} & \dot{0} \\
++1 & +1\end{array}$ & 11 \\
\hline 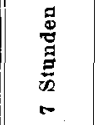 & & & $\begin{array}{l}\dot{0} \\
++\end{array}$ & $\begin{array}{l}+ \\
+ \\
+ \\
+\end{array}$ & + & $\begin{array}{l}+ \\
+\end{array}$ & 11 \\
\hline 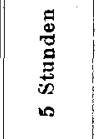 & $\begin{array}{l}\dot{\vec{n}} \\
++\end{array}$ & $\begin{array}{l}\dot{0} \\
++\end{array}$ & + & & $\begin{array}{l}\dot{\hat{ि}} \dot{2} \\
++\end{array}$ & & 11 \\
\hline 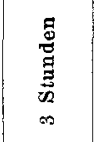 & $+t$ & ++ & + & $\begin{array}{l}+ \\
+ \\
+ \\
+ \\
+\end{array}$ & + & $\begin{array}{l}+ \\
+ \\
+\end{array}$ & 11 \\
\hline 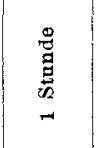 & ++ & $\begin{array}{l}++ \\
++\end{array}$ & $\stackrel{+}{+}$ & $\begin{array}{l}+ \\
+ \\
+ \\
+\end{array}$ & $\begin{array}{l}+ \\
+ \\
+\end{array}$ & $\begin{array}{l}+ \\
+ \\
+ \\
+\end{array}$ & 11 \\
\hline 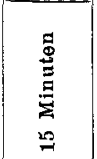 & $\begin{array}{l}+ \\
+ \\
+ \\
+\end{array}$ & $\begin{array}{l}+ \\
+ \\
+ \\
+\end{array}$ & $\begin{array}{l}+ \\
+ \\
+\end{array}$ & $\begin{array}{l}+ \\
+ \\
+ \\
+\end{array}$ & $\begin{array}{l}+ \\
+ \\
+\end{array}$ & $\begin{array}{l}+ \\
+ \\
+ \\
+ \\
+\end{array}$ & 11 \\
\hline $\begin{array}{l}\dot{\vec{\Xi}} \\
\overrightarrow{\mathrm{w}} \\
\dot{0}\end{array}$ & in & 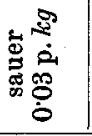 & 官富 & $\begin{array}{l}9 \\
\dot{2} \\
29 \\
0 \\
0\end{array}$ & & 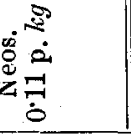 & 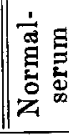 \\
\hline
\end{tabular}


24 Stunden nahezu auf der gleichen Höhe, trotzdem doch eine so geringe Gesamtmenge $(0.03 \mathrm{pr} . \mathrm{kg})$ eingespritzt wurde. Die Erklärung dafür liegt wohl darin, daß sich durch Ausfällung in der Lunge ein reichliches Salvarsandepot mit relativ sehr großer Oberfläche bildet, von dem dann in der Folgezeit dauernd kleine Mengen in das Blut aufgenommen werden. Auf diese Verhältnisse wird unten bei Besprechung der Organe (Lunge) noch näher einzugehen sein. Nach 24 Stunden waren in den meisten Fällen noch geringe Spuren nachweisbar, dann allerdings erlosch die Reaktion vollkommen.

Die alkalische Salvarsanlösung bleibt ungleich länger in erheblicherem Grade im Serum nachweisbar. Erst nach 5-7 Stunden beginnt sie allmählich auf geringe Spuren herabzugehen, vorausgesetzt, daß man, wie auch ich anfangs, zwar frisch bereitete aber $k$ alte Lösung verwendet. Diese Ergebnisse stimmen überein mit den von Gonder schon früher mitgeteilten Resultaten (Zeitschr. f. Immunitätsforschung, Bd. XV, Heft 2/3). Er fand nach $4 \frac{1}{2}$ bis 5 Stunden ein Erlöschen der Reaktion.

Überraschend waren daher die mit ganz frischem noch warmem Reagens gewonnenen Resultate (s. o.). Wie die Tafel zeigt, kann man damit noch geraume Zeit später, 24 bis 48 Stunden, ja mehrere Tage nach der Injektion unter Umständen noch eine Gelbfärbung bekommen.

Das Neosalvarsanserum verhielt sich im allgemeinen genau wie das Salvarsanserum (alkal.), nur erlosch die Reaktion hier nach 24 Stunden meist völlig, nachdem sie auch vorher bereits schneller abgenommen hatte als bei jenem.

Jene Differenz zwischen dem Ausfall der Reaktion mit kaltem und warmem Reagens war nun weiter der Gegenstand eingehender Untersuchungen. Es war auftällig, daß nach einer kurzen Zeit des annähernd gleichen Ausfalles der beiden Reaktionen sich bereits nach etwa 3 Stunden eine Differenz dahin geltend machte, daß die Reaktion K. (kaltes Reagens) allmählich zurücktrat, die Reaktion W. (frisches, noch warmes Reagens) jedoch noch lange Zeit in fast unverminderte Stärke fortbestand, um manchmal erst nach Ablauí von Tagen gänzlich zu verschwinden. Mit normalem Kaninchenserum konnte ich 
trotz vielfacher Versuche eine solche Reaktion niemals erzielen. Von den Differenzen zwischen den verschiedenen Versuchsreihen sehe ich dabei ab, die ja sicher in individuellen Verschiedenheiten der benutzten Tiere ihren Grund haben. Es kann aber nicht unerwähnt bleiben, daß die Reaktion mit $R$. W. zuweilen schwankend war, sodaß sie manchmal ausblieb bei der wiederholten Untersuchung eines Serums, das vorher ganz deutlich positiv reagiert hatte. Ich hatte zuweilen den Eindruck, daB die Reaktionsfähigkeit der Sera mit dem Alter des Serums nach der Entnahme zunehme. Angesetzte Parallelversuche brachten bisher noch keine eindeutige Klärung dieser Frage. Es liegt auf der Hand, daß es von größter Wichtigkeit war festzustellen, ob diese Gelbfärbung mit Reagens W. tatsächlich von Salvarsan herrührte. Man könnte sich ja auch vorstellen, daß vielleicht irgend ein Spaltprodukt des eingefübrten Präparates in dem Serum enthalten sei, ein Gedanke, für den gerade das schwankende der Reaktion zu sprechen schien. Man wird sich hier erinnern müssen, daß nach Ehrlich das Paradimethylamidobenzaldehyd kein eingentliches Reagens auf Salvarsan ist, sondern, daß die in diesem enthaltene Amidogruppe die Reaktion gibt.

Nach Ehrlichs Ansicht ist es nicht wahrscheinlich, daß die Amidogruppe rom Benzolkern losgelöst wird. Dagegen kann man sich sehr leicht vorstellen, daß an die Amidogruppe synthetisch andere Reste verankert werden. So reagieren z. B. Harnstoffderivate nicht mehr mit dem Paradimethylamidobenzaldehyd. Ehrlich meint nun, daß man unter Annahme einer solchen synthetischen Verstopfung der Amidogruppe des Salvarsans sich die Wirkung dẹs warmen Reagens so erklären kann, daß diese locker zu denkende Verbindung gespalten und die Amidogruppe wieder frei wird.

Um nun festzustellen, ob jene durch Verstopfung der Amidogruppe chemisch veränderten Salvarsanreste gleichwohl noch therapeutisch wirksam sind, habe ich mit dem Salvarsanserum Versuche angestellt, welche sich auf früher von Gonder (l. c.) veröffentlichte stützen. G o nder konnte zeigen, daß das Serum von Ratten, denen er Salvarsan intravenös injizierte, in vitro eine Spironemenaufschwemmung derart beeinflußte, daß 
die Spironemen zwar ilıre Beweglichkeit nicht einbüßten, daß aber mit der Aufschwemmung eine Infektion bei Mäusen nicht mehr hervorgerufen werden konnte. Auch an Hühnern erzielte er gleiche Resultate und stellte fest, daß mit dem Erlöschen der Ehrlich-Bertheimschen Reaktion auch diese Wirkung auf die Spironemen aufhörte, also mit $4^{1} \frac{1}{4}$ bis fünfstündigem Serum die Infektionen glatt angingen. Auch $S$ wif t und Ellis veröffentlichten kürzlich (Journal of Experiment. Medz., Vol. XVIII, Nr. 4, 1913) ähnliche Versuche an Spirochaeta duttoni. Sie konnten mit $1,2 \mathrm{ja}$ bis 11 stündigem Serum Beeinflussung von Spirochaeten feststellen.

Meine Versuchsanordnung war folgende:

Je 4 Kaninchen wurden vor der Blutentnahme mit Salvarsan sauer $0.03 \mathrm{pr}$. $\mathrm{kg}$, Salvarsan alkal. $0.075 \mathrm{pr} . \mathrm{kg}$ und Neosalvarsan $0.11 \mathrm{pr}$. $\mathrm{kg}$ gespritzt und zwar so, daß 1, 5, 24 und 48stündiges Serum gewonnen wurde. Von jedem Serum wurden je zwei infizierte Mäuse gespritzt, eine mit $0 \cdot 75$, die andere mit $1.25 \mathrm{ccm}$. Vor der Injektion war bei allen verwendeten Mäusen die Infektion schwach positiv. Gleichzeitig wurde von den Seren die Ehrlich-Bertheimsche Reaktion angesetzt. Als Kontrolle diente das Serum eines unbehazdelten gesunden Kaninchens (siehe nebenstehende Tabelle II).

Aus der Tafel ist deutlich ersichtlich, daß die Heilwirkung im allgemeinen der Ebrlich-Bertheimschen Reaktion und zwar mit Reagens W. parallel geht. Fünfstündiges Salv. sauer-Serum heilte nur in der größeren Menge. Nach 24 Stunden hörte hier wie beim Neosalvarsan der Heileffekt auf. Salvarsan alkal.-Serum heilte jedoch auch in geringerer Menge die Infektion glatt. Die Flüchtigkeit der Neosalvarsanwirkung, eine Folge der leichteren Löslichkeit des Präparates, kam hier also deutlich zur Anschauung.

Länger noch als durch den Heilversuch konnten durch Einwirkung des Serums in vitro auf die Trypanosomenaufschwemmung spezifisch parasitozide Substanzen nachgewiesen werden.

0.5 Salvarsanserum wurde in vitro bei Zimmertemperatur 30 Minuten mit $1 \mathrm{ccm}$ einer Trypanosomenaufschwemmung (Mäuseblut) zusammengebracht, welche 5-10 Trypanosomen 


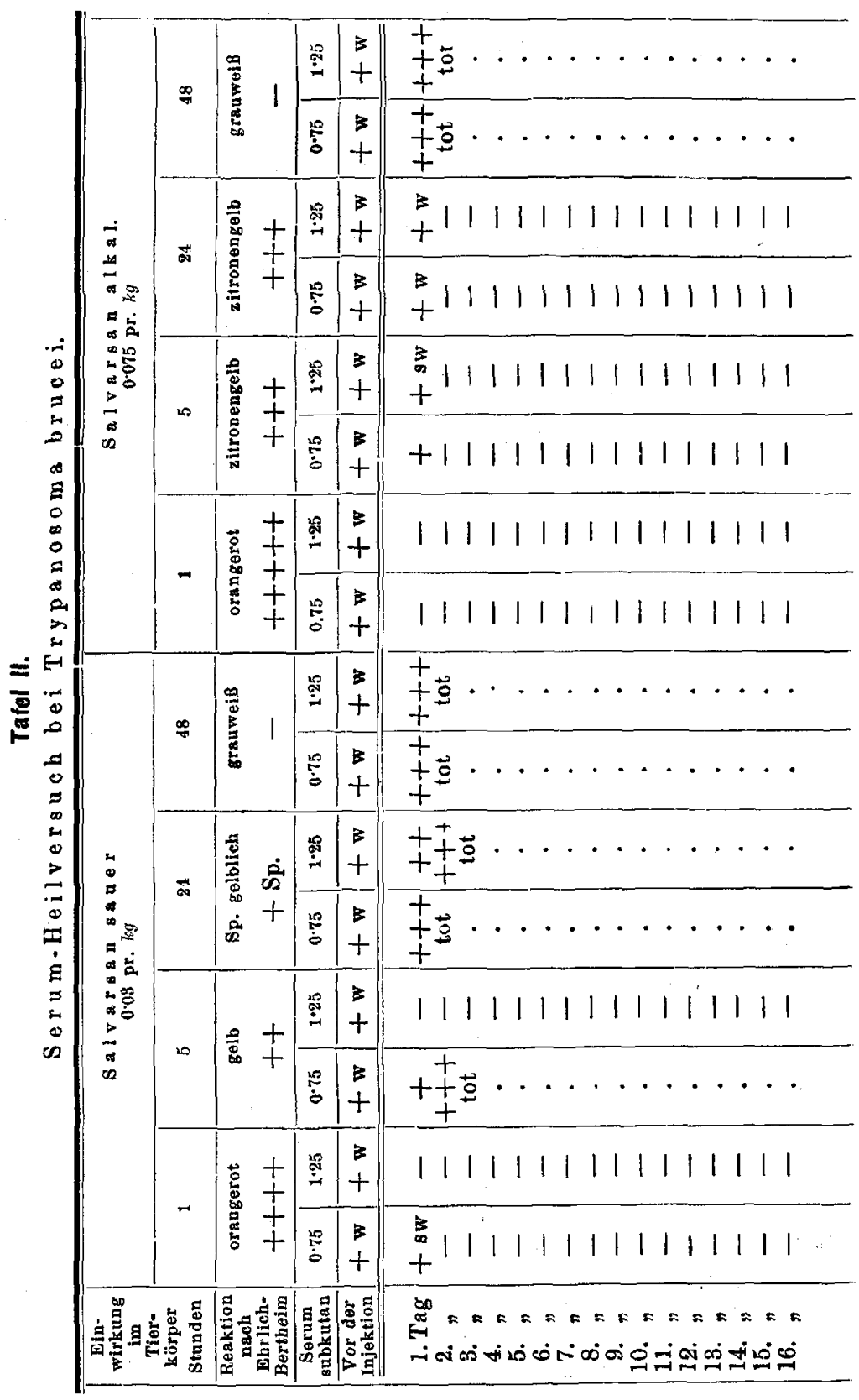

Arch. f. Dermat. a. Byph. Bd. CXX. 


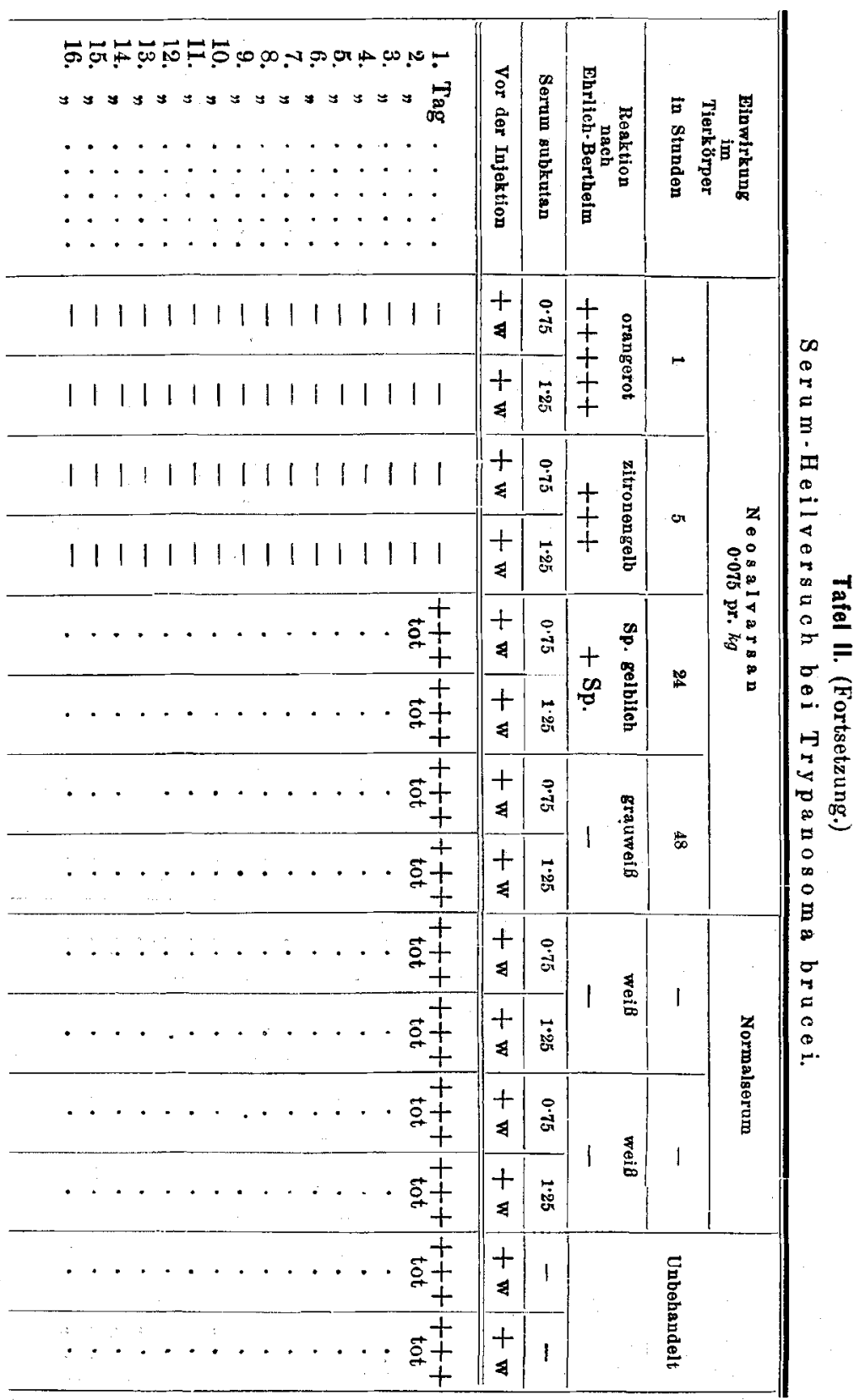


im Gesichtsfeld zeigte. Von dem Gemisch wurde $0.5 \mathrm{ccm}$ Mäusen subkutan gespritzt. Die Trypanosomen waren kurz vor der Einspritzung in allen Röhrchen lebhaft beweglich (siehe Tabelle III).

Bei Salvarsan sauer erlosch die Schutzwirkung bei 24 Stunden. Die Infektion ging hier an, wenn auch verzögert (3 Tage später als bei den Kontrollen). Neosalvarsanserum schützte die Mäuse noch nach 24 Stunden sicher, nach 48 und 72 Stunden fehlte die Schutzwirkung. Am besten waren die Resultate bei Salvarsan alkalisch. Hier wurde bei 48 keine, bei 72stündigem Serum erst am 10. Tage eine Infektion erzielt.

Ein Vergleich dieser Ergebnisse mit dem Ausfall der Ehrlich-Bertheimschen Reaktion zeigt, daß im Heilversuch Sera keine Wirkung mehr hatten, die immerhin noch schwach positive Reaktion zeigten, so Salv. sauer 24 Std. und Neosalv. 24 Std. Als empfindlicher erweist sich hier der In vitro-Versuch, bei dem der geringsten Spur positiver Reaktion auch ein sichtbarer Effekt auf die Trypanosomen entsprach. Man kann also sagen, daß in der Tat die Ehrlich-Bertheim sche Reaktion, mit frischem, noch warmem Reagens angestellt, ein außerordentlich feiner Indikator ist für die Anwesenheit parasitozider Substanzen im Blutserum.

Ich beschränke mich hier auf die Wiedergabe der Resultate lediglich am Tier. Über Versuche mit Menschenserum, wie sie ebenfalls von $\mathrm{Swift}$ und $\mathrm{E}$ llis bereits mitgeteilt wurden, werde ich an anderer Stelle berichten.

\section{B. Organe.}

Über die Verteilung der einzelnen Salvarsanpräparate in den Organen ist alles wesentliche aus den Zusammenstellungen ersichtlich. Es wurden wiederum den Tieren entsprechende Mengen der drei Salvarsanmodifikationen eingespritzt, z. T. in wechselnder Konzentration. Die Entblutung geschah zu den verschiedensten Zeiten nach der Injektion, von wenigen Minuten angefangen bis zu 24 Stunden und darüber (siehe Tab. IV).

Bei der sauren Salvarsanlösung spielte zunächst einmal die Konzentration eine sehr erhebliche Rolle. Es konnten den Tieren nennenswerte Mengen des Präparates über- 


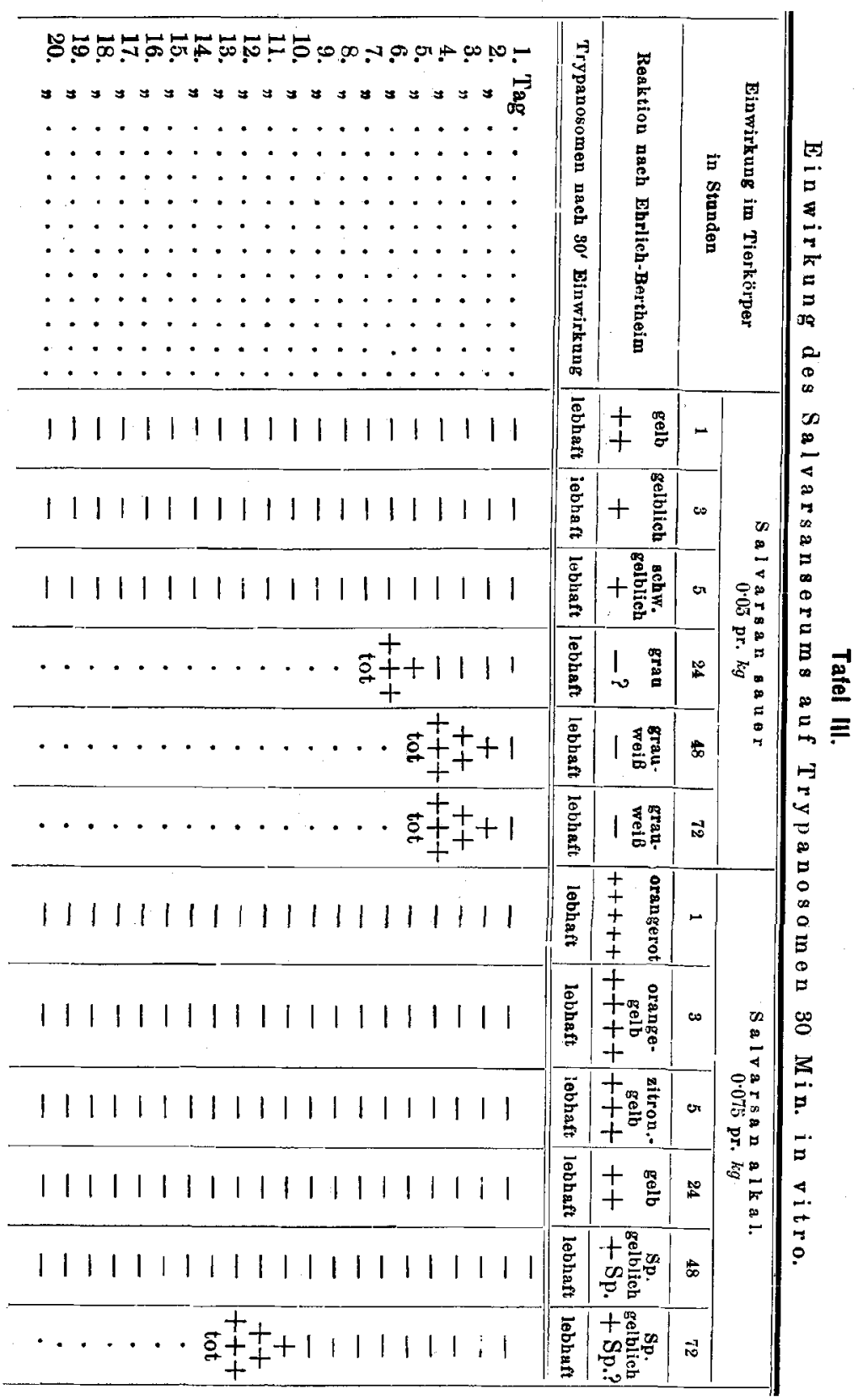


Zur Topographie des Salvarsans und Neosalvarsans.

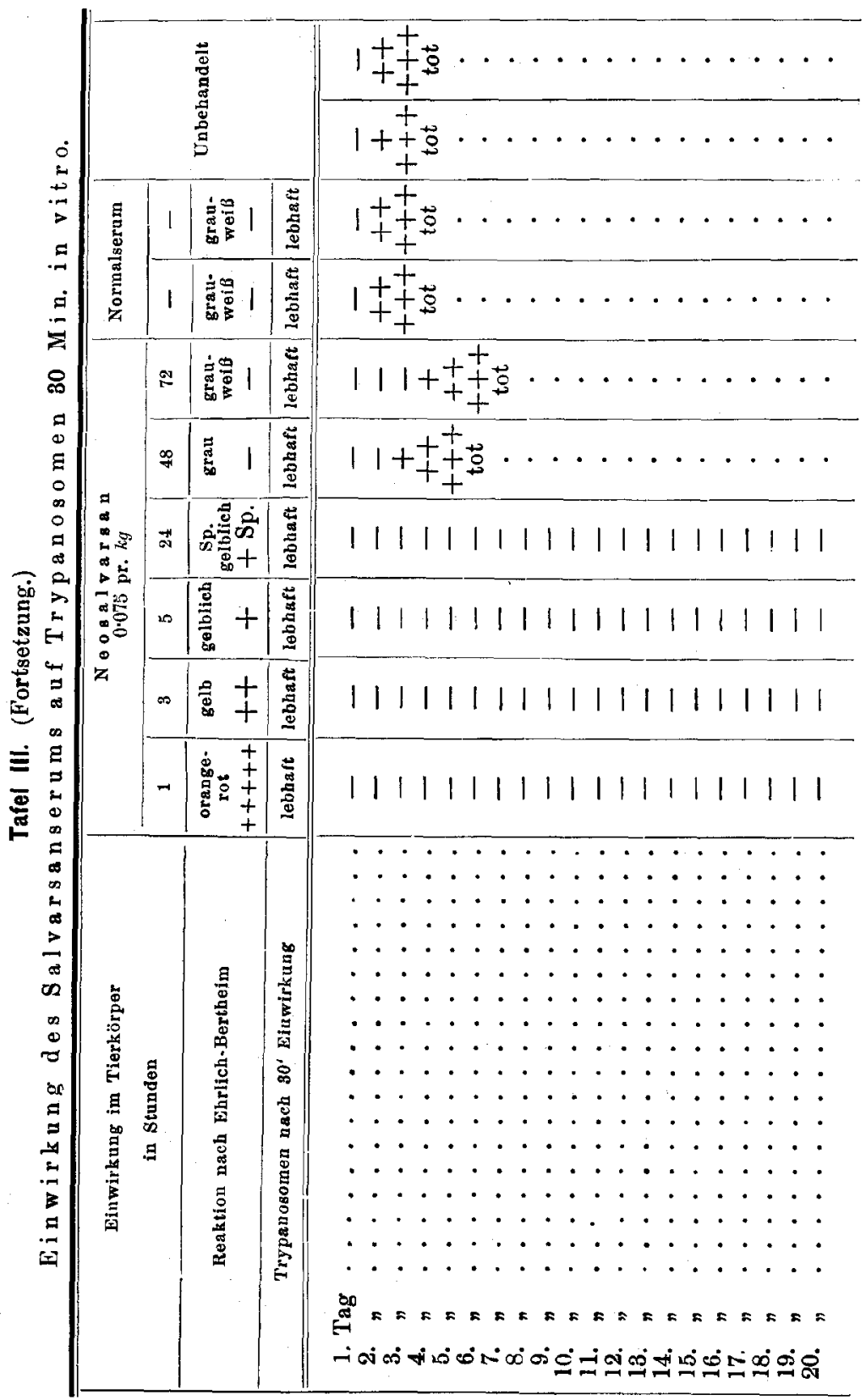




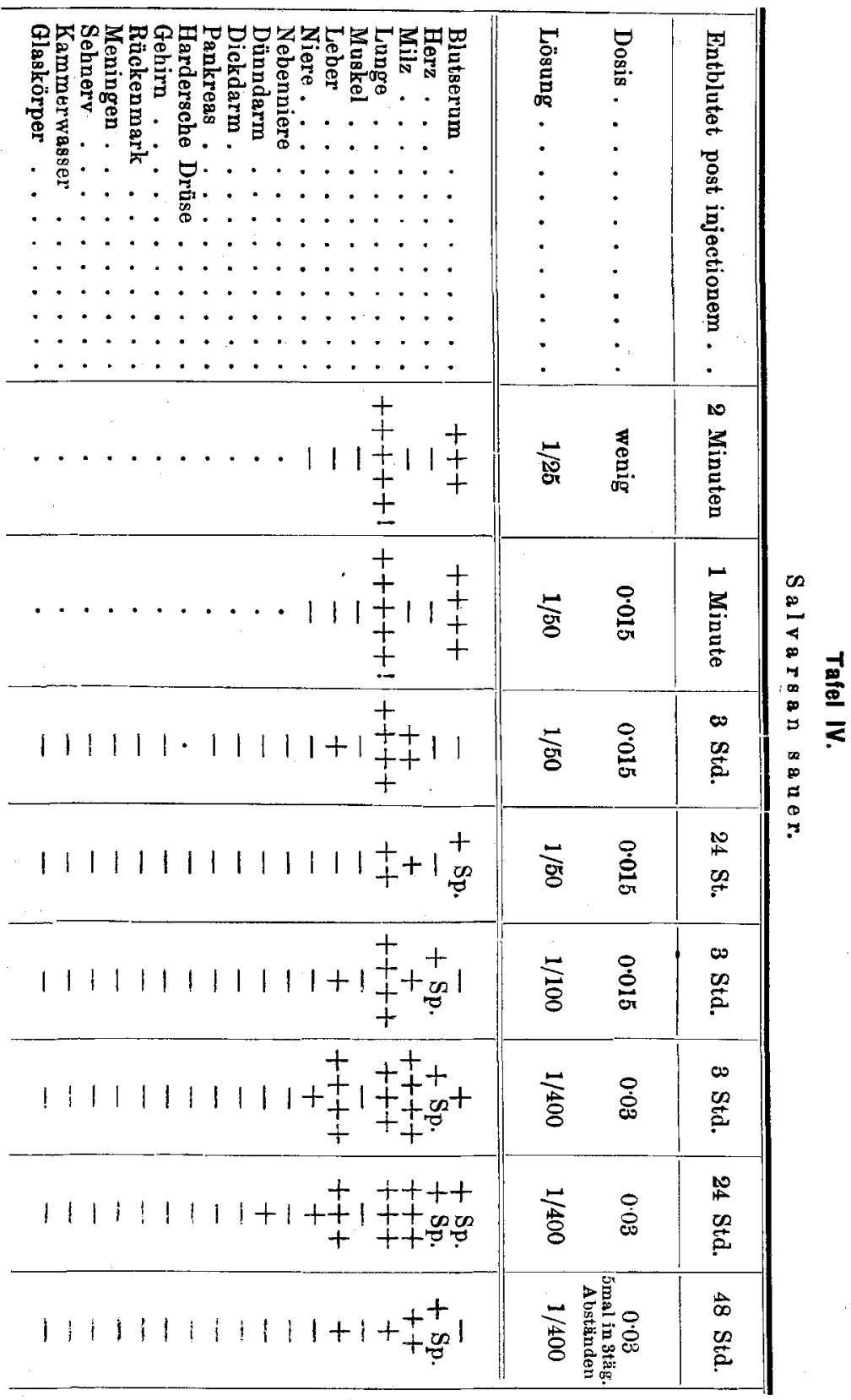


haupt erst in einer Konzentration von 1:50 ab beigebracht werden. Und auch hier mußte das Tempo der Einspritzung sehr verlangsamt werden, um nicht das Tier bereits mit geringsten Mengen akut zu töten. Der Tot trat bei jenen hochkonzentriert gespritzten Tieren ein durch Ausfällung des sauren Salvarsans in der alkalischen Blutflüssigkeit. Die ausgefällten Flocken werden offenbar in den Lungenkapillaren wie auf einem Filter zurückgehalten und verstopfen so schließlich diese feinsten Gefäße vollständig; es kommt zum Verschluß des größten Teils der Kapillaren, Thrombose derselben und zur Aufhebung des Lungenkreislaufs. In solchen Lungen konnte die Anhäufung des Salvarsans in den Gefäßluminis mit dem Reagens sehr schön zur Anschaung gebracht werden. Aus dem grauen Gewebe hoben sich die leuchtend orangegefärbten Gefäßquerschnitte prachtroll ab. Mikroskopisch ließ sich ebenfalls die starke Erweiterung der verstopften Gefäße erkennen. Aus der Betrachtung der übrigen Organe dieser Tiere, welche jenseits dieses Lungenfilters sich befinden, geht hervor, daß das injizierte Salvarsan fast vollständig von dem zuerst betroffenen Organ zurückgehalten wird. Verlangsamt man das Tempo der Injektion erheblich oder setzte man die Konzentration der Lösung herab, so wurde zwar der tödliche Ausgang vermieden, die Lungen blieben aber gleichwohl bei der sauren Lösung stets das berorzugte Organ. Erst bei einer Konzentration von $1: 400$ näherten sich die Verteilungsverhältnisse denen, welche wir bei alkalischer Salvarsanlösung beobachteten, d, h. Leber und Milz nahmen wesentlich an der Speicherung des Salvarsans teil.

Von den übrigen Organen zeigten nur die Nieren gelegentlich eine Spur Gelbfärbung, sonst erschienen alle Organe frei. Man muB also annehmen, daß jedenfalls erheblichere Mengen hier nicht abgelagert werden. Allerdings ist bei Vergleichen mit den Resultaten zu berïcksichtigen, da $B$ der höheren Toxizität wegen von dem sauren Lösung nur erheblich kleinere Mengen gespritzt werden konnten. (Siehe Tabelle V).

Die alkalische Salvarsanlösung zeigte wesentlich andere Eigenschaften. Hier war die Verteilung eine viel gleichmäßigere. Jene Bevorzugung des Lungenfilters ließ sich 


\begin{tabular}{|c|c|c|}
\hline 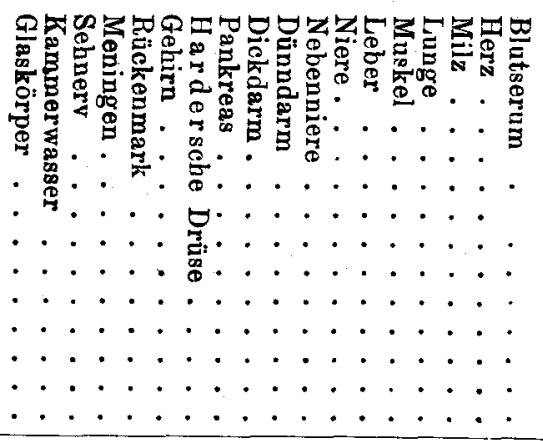 & 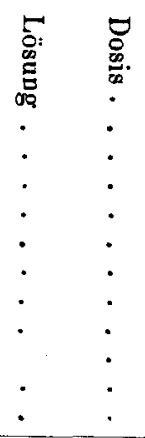 & 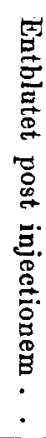 \\
\hline 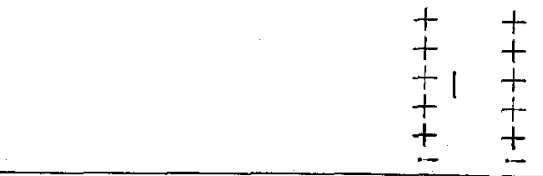 & 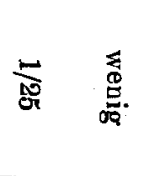 & 葛 \\
\hline 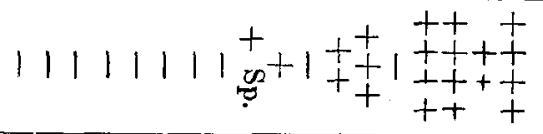 & $\stackrel{-}{8}$ & 它 \\
\hline $11111111+\frac{x^{+}}{0}$ & $\overline{\overline{8}}$ & 它 \\
\hline 1111111 & $\stackrel{⺊}{8}$ & 虫 \\
\hline $111111111++\underset{++}{++}+\frac{+}{+}$ & 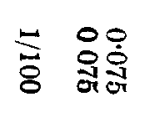 & $\begin{array}{l}\text { 是 } \\
\text { 客 }\end{array}$ \\
\hline $11111111+++$ & 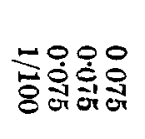 & 总 \\
\hline $1|1| 1 \mid 11+ \pm 1++1++\underset{+}{+}+\underset{+}{+\infty}$ & $\stackrel{乛}{8}$ & $\begin{array}{l}o \\
\stackrel{\infty}{\hat{t}}\end{array}$ \\
\hline$|1| 1|1| 1++\left.||\right|_{\substack{\infty \\
?}} ^{+}|1|$ & $\stackrel{\vdash}{8}$ & 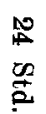 \\
\hline
\end{tabular}


hier nicht konstatieren. Nur ganz konzentrierte Lösungen brachten ähnliche Verhältnisse wie das Salvarsan in saurer Form. Bei einigermaßen erheblicher Verdünnung nahmen stets Lunge, Leber und Milz zu fast gleichen Teilen an der Speicherung teil. Erheblichere Reaktionen ergaben ferner noch die Nieren, Herz und Darm. In den Drüsen (Harder sche Augendrüse, Speicheldrüsen, Pankreas etc.) konnte ich eine Verfärbung nicht finden. Ebenso blieben das gesamte Nervensystem, Gehirn, Rückenmark und ibre Hüllen vollständig frei. Bemerkenswert ist auch, dab die Muskulatur niemals eine Spur Gelbfärbung zeigte (siehe Tabelle VI).

Das Neosalvarsan verhielt sich im ganzen dem alkalischen Salvarsan sehr ähnlich. Die Verteilung war noch etwas gleichmäßiger. Die Nieren zeigten gelegentlich ähnliche Verfärbungen wie Leber und Milz. Auch der Darm reagierte im ganzen stärker als beim Altsalvarsan. Von drüsigen Organen konnten im Gegensatz zum Salvarsan im Pankreas und $\mathrm{Harder-}$ scher Drüse Verfärbungen nachgewiesen werden. Das leicht lösliche Neosalvarsan scheint also mehr als die anderen Präparate im ganzen Körper wirken zu können.

Die auffälligste Abweichung aber von dem Bilde beim alkaliscben Salvarsan ergab die Untersuchung des Nervensystems. Zwar waren Gehirn und Rückenmark wie bei den anderen Präparaten stets absolut frei. Aber die Hüllen des Gehirns und Rückenmarks zeigten bei neosalvarsanbehandelten Tieren eine deutliche Gelbfärbung, die mit der Dosis sich steigerte und durch mehrfache Injektionen systematisch in die Höhe getrieben werden konnte. So war diese Verfärbung am auffälligsten bei einem. Tier, welches dreimal in 3tägigem Abständen je 0.11 Neosalvarsan erhalten hatte. Das mit der entsprechenden Menge Altsalvarsan ( 3 mal 0.075 ) behandelte Tier zeigte keine Spur von Verfärbung der Meningen. Das Neosalvarsan scheint demnach in ungleich höherem Maße seinen Weg zu den Hüllen des Zentralnervensystems zu finden als das Altsalvarsan.

Ein Wort noch über das Ergebnis der wiederholten Injektionen überhaupt (s. Taf. V u. VI). Es war auffallend, daß bei den wiederholt gespritzten Tieren die Reaktion in den Organen, hauptsächlich Leber und Milz, mit der Zahl der Injektionen zunahm, 


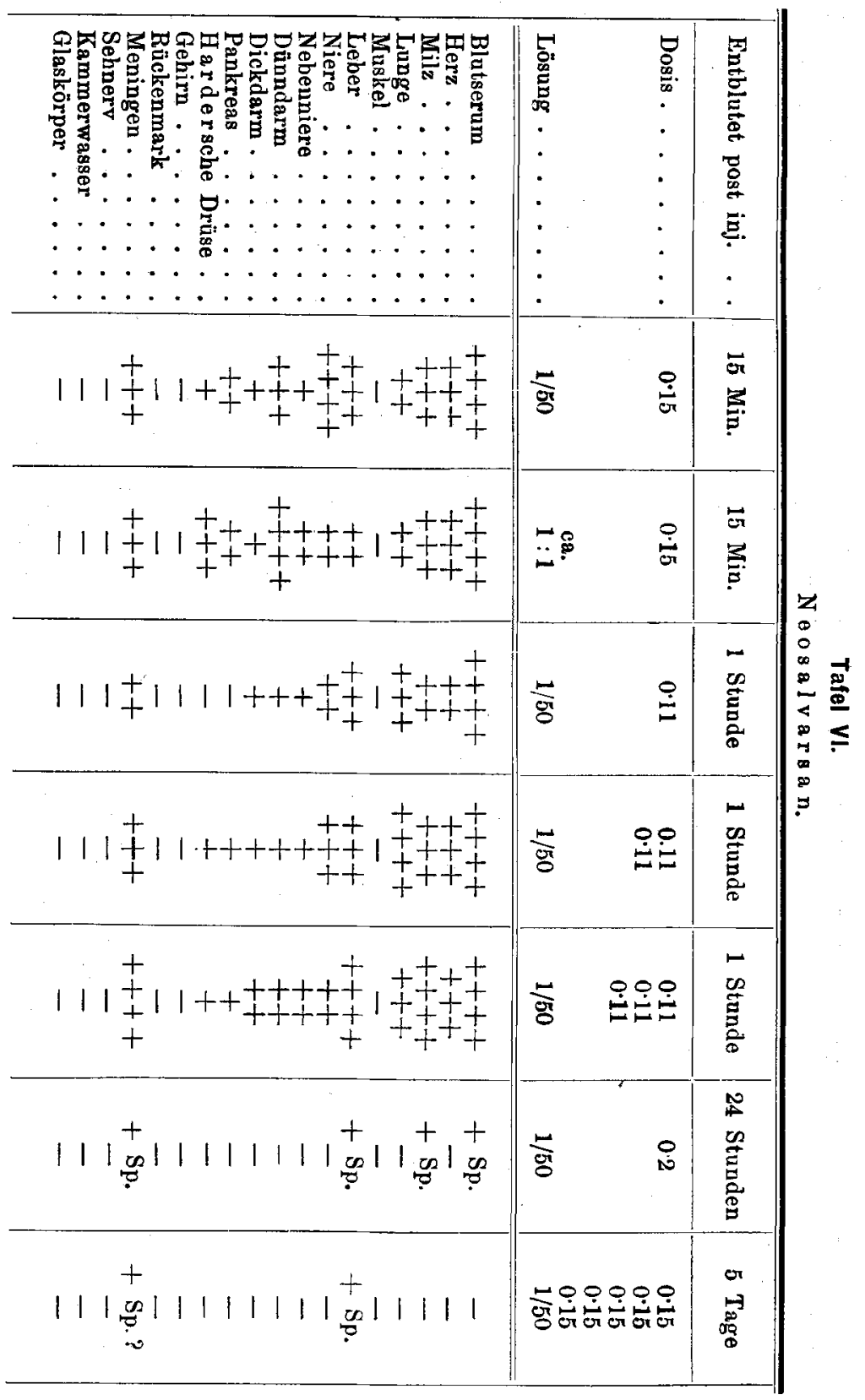


obwohl der zeitliche Zwischenraum (3 Tage) bei einmaliger Einspritzung hinreichte, den letzten Rest einer positiven Reaktion in den Organen zum Verschwinden zu bringen. Man muß also wohl annehmen, daß jene Steigerung des Reaktionsausfalls der Ausdruck ist für eine mit der Zahl der Injektionen zunehmenden Aufnahmefähigkeit der Organe für das Präparat. Eine gewisse Organotropie wird dadurch wahrscheinlich gemacht, so daß auch die intravenöse Therapie in gewissem Sinne als eine Depotbehandlung gelten muß.

\section{C) Einzelne Organe.}

An dem vorstehend zusammengestellten Material wurden nun noch im einzelnen einige Versuche gemacht, um verschiedene Fragen der Ausscheidung des Salvarsans mit Hilfe des Paradimethylamidobenzaldehyds zu prüfen. Wenn auch die Ergebnisse zum Teil negativ waren, so scheint mir manches doch einer kurzen Mitteilung wert zu sein.

So wurden Versuche angestellt, das Salvarsan im Gehirn und seinen Hüllen nach künstlicher Reizung nachzuweisen. Tinel und Leroide (Soz. d. Biolog. LXXIV. 1913. Nr. 18) veröffentlichten ähnliche Versuche, bei denen sie nach vorhergehender Injektion von Natrium nucleinicum Spuren Salvarsan im Liquor nachwiesen. Wir setzten einen Reiz durch einen quer durch das Zerebrum gezogenen Seidenfaden, konnten aber niemals in der Umgebung des Fadens eine Gelbfärbung erzielen. Für die Untersuchung des Liquor cerebrospinalis war das Reagens nicht geeignet, da es sich hier wohl um zu geringe Mengen handelt, selbst wenn unter pathologischen Verhältnissen etwas übergeht. Mehrere Untersuchungen an menschlichem Liquor 12 und 24 Stunden nach der Injektion von Neosalvarsan gaben kein positives Resultat.

Die Ausscheidung durch die Nieren hat naturgemäß stets das Interesse der Kliniker stark in Anspruch genommen. Es lag nahe zu versuchen, das Salvarsan als solches mit dem Paradimethylamidobenzaldehyd im Urin nachzuweisen. Leider erwies sich das Reagens als unbrauchhbar. Eine deutliche Farbreaktion konnte nicht erzielt werden, weder bei Kaninchen noch bei Menschenurinen. Eine schwache Rotfärbung, 
welche gelegentlich auftrat, ist nicht charakteristisch für Salvarsanurin, da sie auch in normalen Harnen vorkommt (Urobilin). Auch Kochen des Urins mit Salzsäure oder Ausschüttelung z. B. mit Amylalkohol ergaben keine Resultate. Wie oben ersichtlich, zeigten die Nieren bei den einzelnen Präparaten in verschiedenem Grade eine Gelbfärbung. Am stärksten war diese beim Neosalvarsan, wo besonders die Markstrahlenkegel zuweilen intensiv dunkelgelb gefärbt waren. Wie ferner bereits Ullmann (l. c.) mitteilte, kann diese Gelbfärbung auch auf der Schleimhaut des Nierenbeckens erhalten werden. Man muß demnach wohl annehmen, daß das Salvarsan jedenfalls als solches die Nieren passiert. Dies wird auch wahrscheinlich gemacht durch die letzten Untersuchungen ron Fränkel$\mathrm{Heiden}$ und $\mathrm{Navassart}$ (Zeitschr. f. experimentelle Pathologie und Therapie. XIII. 3. Heft). Sie benutzten nach dem Vorgehen von A belin die Diazoreaktion zum Fällen desselben und wiesen in dem dabei auftretenden roten Farbstoff As in reichlicher Menge nach.

Salomon und Brown konnten ferner zeigen, daß mit Salvarsanurin, d. h. Urin nach Salvarsaninjektion, Trypanosomeninfektionen bei Mäusen geheilt werden können. (Compt. rend. Soz. Biol. 1912. Bd. LXXIII. H. 29).

Neben der Nierenausscheidung hat in letzter Zeit die dus scheidung durch den Darmkanal erhöhtes Interesse gewonnen, Fränkel und Navassart stellten fest, daß hier sogar erheblich größere Mengen As den Körper verlassen, als mit dem Urin. Wir versuchten dem Salvarsan auch hier mit unserem Reagens nachzugehen. Die Schleimhaut der einzelnen Abschnitte des Magendarmkanals wurden durch Aufträufeln untersucht. Während das alkalische Salvarsan hier nur geringe Reaktionen zeigte, waren die Verfärbungen bei den Neosalvarsantieren wesentlich deutlicher. Am meisten reagierten hier mit einiger Regelmäßigkeit Magen und Dünndarm, während Dickdarm und Mundschleimhaut nur schwache oder gar keine Reaktion zeigten. Naturgemäß waren diese Untersuchungen nicht immer eindeutig, da ja die wechselnde Farbe des Darminhaltes hier des öfteren störend wirkte. Immerhin geht aus den Untersuchungen doch hervor, daß besonders beim Neosalvarsan, aber 
doch auch bei den anderen Präparaten, nicht unbeträchtliche Mengen nahezu unveränderten Salvarsans in den Magen und den Dünndarm ausgeschieden werden. Im K ot konnte ein einwandfreier Nachweis nicht geführt werden. Auch im wäßrigen Filtrat wirkte hier die Farbe des Kotes zu störend. In der Galle konnten niemals Verfärbungen erzielt werden, die auf die Anwesenheit von Salvarsan schließen ließen. Hier wirkte die natürliche Farbe nicht so störend wie man zunächst annehmen möchte. Kontrolluntersuchung mit künstlich beigemengtem Saivarsan ergaben auch bei kleinsten Mengen einen deutlichen Farbumschlag ins Gelbe, so daB ich die Ausscheidung jedenfalls erheblicher Salvarsanmengen direkt in die Galle für unwahrscheinlich halte.

Zu s a m m en fas s end kann man aus den oben mitgeteilten Versuchsergebnissen folgendes ableiten:

Von allen drei untersuchten Präparaten ist die Verteilung im gesamten Körper beim Neosalvarsan am gleichmäßigsten. Nur wenig steht ihm in dieser Beziehung nach das alkalische Altsalvarsan, während das saure Salvarsan eine besondere Vorliebe fiir die Lungen zeigt, durch die es in gefälltem Zustand wie auf einem Filter zuriickgehalten wird. In konzentriertem Zustand (1:25) geschieht dies auch mit dem alkalischen Salvarsan. Neosalvarsan verteilt sich auch in höchster Konzentration (1:1) ganz gleichmäßig.

Schon kurze Zeit nach der Einspritzung werden alle Präparate zum gröBten Teil von den Organen gespeichert. Lunge, Leber und Milz haben hieran den größten Anteil zu fast gleichen Teilen. Hier wird also ein Depot mit großer Oberfläche gebildet, aus welchem nun der Blutstrom in der Folgezeit dauernd kleinere Mengen auslaugt. Diese im Blute enthaltenen Mengen kommen zur klinischen Wirkung. Beim sauren und alkalischen Salvarsan hält diese Wirkung am längsten an, unter Umständen bis zu 3 Tagen. Beim Neosalvarsan ist das Depot in der Hauptsache bereits nach 24 Stunden erschöpft.

Das Salvarsan wird zu gutem Teile wahrscheinlich unverandert durch die Nieren, ganz besonders aber durch den Darm ausgeschieden. Die Mengen im Darm sind so erheblich, daß bei Störungen der Darmfunktion wohl an Bildung stark toxischer 
(Oxydations-)Produkte gedacht werden muß, die eventuell, resorbiert, schädliche Wirkungen entfalten können.

Durch mehrfach wiederholte Injeltionen wird die Aufnahme fühigkeit der speichernden Organe offenbar erhöht, ihre depotbildende Eigenschaft also gesteigert.

Das Nervensystem bleibt bei allen Präparaten selbst ganz frei, nur das Neosalvarsan zeigt für die Hiillen des Zentralnervensystems eine gewisse Vorliebe. Es wird also besonders da gute Dienste leisten, wo die Beeinflussung eines meningealen oder zerebralen Herdes beabsichtigt ist, denn es ist anzunehmen, daß aus den Meningen dann auch Spuren in den Liquor übergehen, was beim Altsalvarsan nicht in dem Maße wahrscheinlich ist.

Eingelaufen am 21. April 1914. 